\title{
Research on and Application of the Tendency of Appreciating Ugliness Consistent with the Change of Times
}

\author{
Shirui Xue \\ College of Journalism and Communications, China West Normal University, Nanchong, China \\ Email: 644354662@qq.com
}

Received 14 April 2016; accepted 25 April 2016; published 28 April 2016

Copyright (C) 2016 by author and Scientific Research Publishing Inc. This work is licensed under the Creative Commons Attribution International License (CC BY). http://creativecommons.org/licenses/by/4.0/

(c) (i) Open Access

\begin{abstract}
The tendency of appreciating ugliness was inevitably born in the context of aesthetics of the times. Its research content includes the contemporary culture of tendency of appreciating ugliness, aesthetic pursuit of audients, role performance, etc. This impact of the tendency of appreciating ugliness has different degrees and levels, but they all almost penetrate into our lives without exception. Appreciating ugliness not only is a simple appreciation course from ugliness to beauty, but also involves how the contemporary culture, technology and art can create the substantial content consistent with "aesthetic" standards of the times. "Ugliness" tendency in the field of theory study is less, only in the stage of slow development, theoretical study on the lack of integrity, systematic, and relatively lags in the practice application. This article aims at the "ugliness" under the globalization phenomenon by using the method of comparative study and the method of longitudinal development at home and abroad from different periods of ugly and beauty, beauty and ugliness and the root cause analysis and comprehensive, systematic generalization.
\end{abstract}

\section{Keywords}

Ugliness, Appreciating Ugliness, Logical Evolution

\section{Introduction}

Under the fast pace of fast food culture "ugliness" tendency has brought the public entertainment the enjoyment on the vision, this article through to contemporary aesthetics principle of Wangheng Chen, Zhang's "theory of aesthetic culture, Zhou Xian cultural modernity and aesthetic issues, Xiaobin Yang" negative aesthetics, "Hongyue Wang's" aesthetic against: pioneer of literature and art thoughts related to the aesthetic theory of plane in 
depth analysis, and combined with different period of Chinese and western aesthetics development has carried on the profound analysis summary. To the audience in the tendency of "ugliness" physiological and psychological perception changes made inductive research, from the micro and macro is pointed out that the characteristics and laws of "ugliness" tendency, summed up the complete set of theory of ugliness and values system. In this paper, the origin and development of ugliness and beauty as the main line, illustrates the aesthetic transition fit era ugliness and the creation of the basic model, characteristics and development strategy, therefore, the study of ugliness and tendency is contemporary and innovative.

\section{Logical Evolution of the Concept of "Ugliness" in the West}

\subsection{Ancient Time-Rejection Period of Ugliness}

"Beauty", "harmony and beauty" is the highest principle in the consciousness of western classical Greek. The supreme and unarguable position of the highest principle of "beauty" causes the highly exclusive ugliness, which becomes the opposite side of "beauty". Things imitated and created by artists have to be more harmonious and beautiful, and shall not be uglier than before. The people who violate the regulation will be punished correspondingly (Chen, 2009: p. 20). This is the legal treaty expressly stated of Thebes. Even when ugliness needs or has to be applied to the artistic creation, the prerequisite is that the "ugliness" shall be beautified first. At the same time it shall not break or destroy the part of the harmony and beauty with the principle of pleasure. For example, Laocoon Group, the world famous sculpture is suffering and trampled. However, the painful, struggling and distorted body, appearance, fear, grief or despair is not shown, in order to follow the highest principle of harmony and beauty and keep the beautiful model (Jiang, 1993: p. 35). Winkelmann called it "the noble innocence and serene greatness".

\subsection{Contemporary Times-Development Period of Ugliness}

Due to the uplift of main body, the consciousness of personality and the liberation of people, a lot of ugliness directly enters the art creation. Aesthetic was created by Baume, a German aesthete, in the $18^{\text {th }}$ century. He defined beauty as the perfection of the perceptual knowledge itself. He believed that perfect appearance and shape were obviously beautiful, and the corresponding imperfect was ugly. As a result, he excluded the ugliness in the aesthetic perceptual sense out of aesthetics, but he didn't reject the saying that ugliness could be the object of "aesthetics" and ugly things could be considered in a beautiful way; and beautiful things could also be considered in an ugly way. In terms of art, Rosencrantz believed: "Art should accept ugliness, but ugliness cannot exist in isolation in art". But the ugliness in this period was not entirely independent or in the category of "aesthetics".

\subsection{Modern Times-Rise Period of Ugliness}

In modern times, the rise period of ugliness, ugliness was officially promoted into the category of independent aesthetics. Since the $19^{\text {th }}$ century, with the more and more turbulent situation, the capitalist society had the chaotic situation, leading to people's psychological distortion and intensified conflicts. Due to the productivity progress and continuous development of science and technology, the natural social form had the polarization of high degree of material civilization and extreme spirit crisis. Such real structural contradiction in the capitalist society deteriorated the relationship between beauty and ugliness. If beauty is modern and lofty, ugliness is backward, vulgar, and the foil of beauty. Thus it is concluded that "the beauty with the purpose of harmonious and beautiful results consistently always denies the existence of ugliness; however, in the large range and environment of ugliness, the result and purpose of beauty is always to deny beauty". The transformation and change between beauty and ugliness shows that the ugliness has upgraded to the category of independent aesthetics, and the traditional aesthetics have been to reverse side-modernistic beauty and ugliness. For example, Baudelaire's Flowers of Evil, the masterpiece in this period, gave up the noble and elegant beauty. This period is not only in the aesthetic category, but also in the art category. Ugliness entered an independent aesthetic category. In other words, this period was dominated by ugliness. Ugliness was settled in aesthetics and art. Ugliness got a qualitative leap. Western literature and art have completed the transition from "aesthetic" to "ugliness". Modern art pushed the ugliness to the center of the "aesthetic". That is to say, in modern aesthetics and art, ugliness has upgraded from traditional foil, edge position or simple ugliness in form and content to the area of modern new 
beauty and ugliness, so that ugliness becomes a truly independent aesthetic category.

\section{Logical Evolution of the Concept of "Ugliness" in China}

China grasped the dialectical relationship between beauty and ugliness earlier than the west. In the Chinese aesthetics history, Chuang Tzu was the first to talk about the ugliness. He had unique views on beauty and ugliness early in the Pre-qin Era. Taoism advocates "taking true as beauty", "getting spirit from ugly form", "equal beauty and ugliness" and other views on beauty and ugliness in the Taoist thought, which determined outstanding characteristics and fate of "ugliness" in Chinese culture. The Taoist thought of Chinese study of ugliness has a long history. Beauty art, beauty thought, ugliness art and ugliness thought exist simultaneously and connect seamlessly (Bosanquet, 2001: p. 78).

\subsection{Confusion Period of Beauty, Ugliness, Good and Evil}

In early views on beauty and ugliness culture in China, "beauty, ugliness, good and evil were confused". For example, Mr. Li Zehou used "ferocious beauty" to show and summarize the views on beauty and ugliness in this period. Confusion of beauty, ugliness, good and evil means that aesthetics and ethics are not separated and in a state of chaos. For example, Lv's Spring and Autumn Annals describes the taotie design on ancient bronze wares in China as follows. "It only has head and has no body, and it dies before it swallows a man". Taotie is a fierce, ugly and ferocious deformed animal image. Such ferocious, bizarre, violent and horrific Taotie with an animal face is in stark contrast with great, kind-hearted, kind, heroic and brave human beings. It tells people that they actually can conquer and control the strong world.

\subsection{Interconversion Period of Beauty and Ugliness}

The aesthetic view on interconversion of beauty and ugliness of Chuang Tzu in the pre-Qin period in China tells the world that ancient aesthetics of China can convert into each other under certain conditions. For example, some poets pay attention to the exploration of writing technique and style, and look at performance and roles of ugliness from the perspective of artistic style. For example, Han Yu used young and hard words and poems to depict horrific, bizarre and dark things in Gift to Zhangshiba during Illness, Chirping Wild Geese and other poems. In other words, the poetic "beauty" was shown through "ugly" form of things; on tomb murals, stone reliefs and portrait bricks brick in the Han Dynasty, reshaping and variation means and methods were applied to draw a lot of gods, spirit, people and things with distorted and exaggerated form, so that the forms of all kinds of things in the natural artistic creation have simple and vigorous style and seem "not ugly and funny"; in the paintings of Zhu Da in the Qing Dynasty, we can see a lot of wild, bizarre and abrupt models and strange images. These images are based on natural sights such as landscape, stones and birds. They are used to express the painter's restless mood and strong passion (Croce, 1989: p. 47). It seems that in the interconversion period of beauty and ugliness, we still can see that art creation retains the view of "focusing on beauty and looking down upon ugliness". Showing ugliness through art is same to showing beauty through art. We highlight "ugliness" to show "beauty", and show a positive and progressive idea in the natural society, so as to cultivate people's interest, cultivate people's sentiment and comfort people's heart. Therefore, it can be concluded that the ultimate purpose of "ugliness" is still to better appreciate, highlight, pursue and praise beauty. Ugliness is only a kind of means and method of art creation, but not the purpose of art creation.

\subsection{Prominence Period of Ugliness}

In the period of capitalism germination in China, along with the surge and rise of romantic and new social ideological trend, artists push ugliness into people's social life and the public's aesthetic vision as a powerful means, express people's flame and rupture, and increasingly emphasize on ugliness as a disharmonious and negative factor, but not simply considered ugliness as the foil and supplement of beauty as before. Ugly, crazy, coarse, strange, wild, stupid and other ugly artistic styles were mentioned, praised and proposed by Liu Xizai, the last master of classical literary theory in China. "Strange stones treat ugliness as beauty. If they are extremely ugly, they are extremely beautiful”. Ugly, crazy, coarse, strange, wild, stupid and other artistic ugliness once rejected in the traditional art began to become popular in the late Qing Dynasty, and entered people's vision and consciousness domain of "appreciating ugliness" in a large scale. For example, in Nuwa Refining Stones, a famous 
painting of Ren Bonian, the beautiful goddess creating human is painted as hour-glass, course, hard and strange stones. Such ugly consciousness form just regards ugliness as a part of the aesthetic. It is a kind of breakthrough and progress, but there are still differences from the western modern philosophy and social basis of "appreciating ugliness".

\section{4. "Ugliness" Becomes Comparison between China and the West in the Independent Aesthetics}

\subsection{Objective Realistic Conditions under Which “Ugliness” Becomes Independent Aesthetics in China and the West}

From the end of the $19^{\text {th }}$ century to the beginning of the $20^{\text {th }}$ century, the bourgeoisie's dismemberment of the nature and people's commonly suppressed greed extremely expanded. Along with devastating disasters and negative brought by two world wars to people's psychology and physiology, people living in "separated", "chaotic", "crazy", "disabled", "abnormal”, "messy and broken" natural society thought that the normal social and production life was just a thing in the past in the memories. In such "crisis reality", artists deeply felt this strange, desolate and terrific world. They were faithful to their own feelings. Since then, they never used beauty to express their artistic creation, but fought in the despairing, lonely, desolate, terrific and strange natural society. They chose to directly face the decadent, decayed and separated real state in the natural world, and boldly expressed their despair, loneliness, confusion and other negative emotions, so that art broke through the harmonious beauty in the traditional art and accepted the ugliness. It is necessary for art explore and discuss about "ugliness".

"Ugliness" became an independent aesthetic category in China. The objective reason was the indirect influence and introduction of western countries. The method and theory of artistic creation in China have been influenced by western modern and postmodern thought. The decadent social morality, lifestyle and values and advanced science and technology of the west deteriorated social morality and morality. Therefore, ugliness became a widespread phenomenon in China with the uniqueness and commonality of objective realistic foundation. From the 1960s to the 1970s it was crazy, extreme, bizarre, terrific, irrational and distorted. After the reform and opening to the outside world, "the strong and the fit survive", causing the rapid development of the socialist market economy. People are required to constantly strive and fight, so that people have common psychological contradictions, anxiety, conflict, loss and depressive feeling.

\subsection{Subjective Conditions under Which "Ugliness" Becomes Independent Aesthetics in China}

First, ugliness enters the independent aesthetic category in China and the west. The subjective and the key reason is that the public groups which could create, appreciate and love the ugliness appeared and were born in China and the west. Ugly works created by artists were art appreciated and accepted by the public. People started to go to the negative side of beauty, and create the public for the negative beauty, which made negative beauty possibly exist in the independent aesthetic category.

Second, due to the improvement of self-awareness of main body and new awakening of self-consciousness of human, people began to fully explore and deeply grasp the irrational existence such as people's instinct and sexual passion. After thought liberation, modern irrationalism in the west pointed out after study and analysis: "The outstanding human nature which needs to be highly emphasized on is irrationality. We should respect human nature and admit the existence of irrationality of the people”. Therefore, in this period artists began to show the irrational side of art in their works of art, and use the ugliness opposite to beauty for multi-polarization and open-mindedness creation. It is the impact, reform and liberation of the modern art aesthetics. The people repressed for a long time were attention to and praised. Therefore, ugliness must be praised, thus having the independent aesthetic category and status.

\section{5. "Aesthetics" and "Appreciating the Ugliness"}

\section{1. "Aesthetics"}

First, "aesthetic" is a kind of special form and means to know the world in a non-utilitarian, vivid and emotional way formed between people and the society, people and the nature. "Aesthetics" will not get the praise of the 
society for a long term generally in terms of the unity of sense and sensibility, subjective and objective, and the pursuit of truth and development. We should constantly improve the ideological and mental state of people, promote the development of harmony and beauty of people, create a harmonious and beautiful world, and make the world a better place because of us. This is the basic idea of "harmonious" aesthetic concept; second, "aesthetic" is a process in which the audiences judge the beauty and ugliness of morphological characteristics of everything. In other words, the subjective psychological activity process of audience is a kind of "appreciation of the beauty", and audiences' views on things according to their own requirements for certain things. Therefore, "aesthetic" is inexorable objective. On the other hand, at the same time, "aesthetic" is also subject to objective factors. Especially that the audiences' region, times and background will have considerable impact on their criteria of judgment. In the 1950s, for example, in Disney animation Snow White Snow White and the seven dwarfs represent the model images of the true, the good and the beautiful.

"Appreciating the beauty" is one of the unique mental activities of human, and a way to master beauty spiritually of human. It includes two aspects, which are creation and appreciation of beauty. Animation audiences' "aesthetic" mentality is talked about in terms of visual and sound effect and appreciation effect. Animation audiences' "aesthetics" include emotional "aesthetic" and visual "aesthetic". Emotional "aesthetic" is the subject's cognition trends and special feelings of a kind of beauty brought by the object of the specific "aesthetic" value. "Aesthetic" is the visually vivid, smooth, gorgeous and beautiful image, which can bring the audiences the feeling of pleasure and entertainment on the vision. The creation of both traditional hand-drawn animation and modern computer animation is based on the visual "aesthetic" of theme of film.

\section{2. "Appreciating the Ugliness"}

"Appreciating the ugliness" means that the form, content and nature of "aesthetic object" show the phenomenon such as ugliness, distortion, deformation, bizarre and strangeness. In today's society it constantly shocks the audiences' visual stimulation and psychological needs and pursuit, and cause intense conflict in emotions of audiences. "Appreciating the ugliness" is the opposite side of "aesthetics", and beauty temporary psychological and physiological senses and demand meeting of audiences treating ugliness as beauty. As an opportunity, it boldly and rightfully became "appreciating the ugliness" in the field of art aesthetics. Since then, it changed into an unchanged truth and concept. Frankly speaking, "appreciating the ugliness" has subjective and objective meaning. Subjectively, "appreciating the ugliness" refers to the audiences' appreciation, criticism, transformation, judgment, evaluation, tolerance and other capacities of ugliness. Objectively, it refers to grasping the essence and characteristics of the ugliness, and the activity of "appreciating the ugliness" as the objective object in the changing social formation.

However, "beauty and ugliness" and "aesthetics and appreciating the ugliness" are not the concept in the equivalent sense. "Beauty and ugliness" focus on characteristics of things in terms of object, and "aesthetics and appreciating the ugliness" focus on the intrinsic attributes of things in terms of subject. With the change of the times and things for aesthetic and appreciating the ugliness, the connotation of aesthetic and appreciating the ugliness also constantly changes. Chinese and western treatment of appreciating the ugliness has some differences. The Chinese standard for appreciating the ugliness is as follows. "Beauty is shown and promoted with ugliness, so as to achieve the purpose of cultivating". In the west, in the "appreciation of ugliness", most of the time the ugliness is appreciated and tasted as a special kind of beauty. It always brings people much spiritual entertainment and happiness like the clown in the circus. Nietzsche said: "In the area of any kind of art, in addition to beautiful and elegant soul art, there are ugly and evil souls. Perhaps such art is the most heart-shocking".

Beauty is shown or promoted with ugliness, or the ugliness is appreciated specially. They are profoundly, incisively and vividly shown in 3D animation works. For example, the exaggerated, bizarre, terrific and ugliness models in Boonie Bears and Monsters Inc bring happy, exciting and wonderful quick entertainment. "Appreciating the ugliness" in the character design of 3D animation completely subverts beautiful, lovely and vivid animation role models in the traditional animation art. After appreciating the ugliness, the role models appreciating the ugliness create a different physical sense and psychological simulation demand and wonderful visual enjoyment for audiences.

\section{Origin of "Appreciating the Ugliness"}

As an appropriate means, consciousness of "appreciating the ugliness” subjectively expresses the social mental- 
ity conforming to characteristics of the times. Consciousness of "appreciating the ugliness" and the social development in different periods interact as both cause and effect. For example, in China due to the despotic "harmony and beauty" in the mainstream culture in the special social and historical stage, "ugliness" has long been excluded from the mainstream aesthetic value system, and "appreciating the ugliness" has no space. The result is that "appreciating the ugliness" is only the short existence to achieve the goal of "aesthetic". In this kind of living environment, "appreciating the ugliness" is buried, covered and abandoned. It becomes a killed, covered and marginalized reference and aesthetic standards serving as foil of "aesthetic".

In the present fierce real social life full of contradictions, we tend to see appreciation of the ugliness, rather than aesthetic, because the current appreciation of ugliness conforms to the law of development of the times and the pursuit of psychological and physiological values of audience. Along with the rapid development of science and technology, and the progress of human society, appreciating the ugliness appeared in music, painting, sculpture and other forms of art. "Appreciating the ugliness" began to replace the "aesthetic" and become the prominent feature of the modern mainstream art development, such as Venus de Milo, Work No. 3 and Uneasy. In the modern society life, appreciating the ugliness and aesthetic should complement each other and development together. They are both necessary. "Appreciating the ugliness" is to highlight the beautiful form of things better (Zhang, 2003: p. 15). The aesthetic is to highlight and deny the ugly form of things. Appreciating the ugliness refers to the subject's high and rational judgment and examination of the form of the object, rather than just distinguishing between beauty and ugliness of appearance. Contemporary aestheticians began to study and focus on appreciating the ugliness. From the 1990s to now, the theory of appreciating the ugliness has been used in various fields all over the world, and presents the diversified trend of development. It has been basically accepted, appreciated and pursued by the public. Contemporary audiences are required to judge, appreciate and pursue the development form and characteristics of things in artistic aesthetics from "aesthetic", "appreciating the ugliness" and other aspects. Ugly things could be considered in a beautiful way; and beautiful things could also be considered in an ugly way.

If the melting and lovely image characteristics in traditional animation is the animation role modelling "aesthetic", the trend in recent years, bizarre, exaggerated terror, deformity of the $3 \mathrm{~d}$ character animation image is called the "ugliness". For example, One of the shrek looks ugly heroine- the Philippines, but in fact she has a kind, enthusiasm, integrity, a heart that loves is; At the same time, The castle looks ugly, but also fell in love with the visitor, is full of quirks, afraid of trouble and has a part of the world citizen hero-tradesmen shrek. In the movie shrek also have a serious and responsible, full of obsession, kind-hearted, brave smart personality traits. However, "Shrek 2" the handsome prince, prince charming, although handsome charming appearance, but has a heart the sinister and vicious, trivial. So ugly things could be considered in a beautiful way; and beautiful things could also be considered in an ugly way.

\section{Conclusion}

This paper summarizes the logical evolution of the concept of "ugliness" from the ontology, and subjective and objective conditions under which "ugliness" becomes an independent aesthetic category in China and the west. The process from the rejection of "ugliness" in the art aesthetics from to the independent aesthetic category in modern times is also summarized. The phenomenon and values of "appreciating the ugliness" conforming to the aesthetics of the times are deeply analyzed. At the same time, a systematic theoretical system is also provided to the research and development of "appreciating the ugliness", application fields and promotion value of "appreciating the ugliness" in today's social life are discussed about, and the future development trend and existing problems of "appreciating the ugliness" are described.

\section{References}

Bosanquet, B. (2001). History of Aesthetics. Guilin: Guangxi Normal University Press.

Chen, F. Z. (2009). The Rise of Ugliness in the Modern and Postmodern Context. Social Sciences Review.

Croce (1989). Aesthetic Principle. In: Zhu, G.Q., Translated, Foreign Literature Publishing House.

Jiang, K. Y. (1993). New Discussion about Aesthetics. People’s Literature Publishing House.

Zhang, J. (2003). Discussion about Aesthetic Culture. Beijing: Beijing Broadcasting Institute Press. 